Received:

$21-\mathrm{VII}-2021$

Accepted:

$25-\mathrm{X}-2021$

Published Online:

19-XI-2021

\section{Association Between Subjects with Newly Diagnosed Rheumatoid Arthritis and Dental Caries}

\section{Asociación entre sujetos con artritis reumatoide recientemente diagnosticada y caries dental}

Ana Gabriela Sánchez-Medrano MSc ${ }^{1}$; Fidel Martínez-Gutiérrez PhD2;

Marco Ulises Martínez-Martínez MSc ${ }^{3}$; Marco Felipe Salas-Orozco PhD4; Lorena Dafnee Villa-García MSc ${ }^{5}$; Nuria Patiño-Marín PhD 6

1. Program of Doctorate in Dental Sciences, Autonomous University of San Luis Potosi, S.L.P., Mexico. https://orcid.org/0000-0003-2168-909X

2. Program of Doctorate in Dental Sciences, Autonomous University of San Luis Potosi, S.L.P., Mexico. https://orcid.org/0000-0002-2760-8273

3. Rheumatology and Immunology Unit, Central Hospital "Dr. Ignacio Morones Prieto", San Luis Potosí, S.L.P., Mexico. https://orcid.org/0000-0001-8738-8519

4. Program of Doctorate in Dental Sciences, Autonomous University of San Luis Potosi, S.L.P., Mexico. https://orcid.org/0000-0002-1947-0155

5. Program of Doctorate in Dental Sciences, Autonomous University of San Luis Potosi, S.L.P., Mexico. https://orcid.org/0000-0001-5852-2141

6. Program of Doctorate in Dental Sciences, Autonomous University of San Luis Potosi, S.L.P., Mexico. https://orcid.org/0000-0003-0056-5901

Correspondence to: Dra. Nuria Patiño-Marín - 1nuriapm@gmail.com

ABSTRACT: Alterations in saliva, temporomandibular joint disorders, dysphagia, Sjogren's syndrome, dental caries, periodontal disease, and tooth loss have been identified in patients with Rheumatoid Arthritis. The aims of this research were 1) to study the association between newly diagnosed rheumatoid arthritis and dental caries and 2) to identify most frequent teeth with caries in study groups. A descriptive pilot study was performed. A total of 620 participants were evaluated, 29 met the selection criteria. The subjects were divided into 2 groups: 13 subjects with newly diagnosed rheumatoid arthritis and 16 subjects without rheumatoid arthritis. Salivary parameters, DMFT index, care index, FS-T index and Treatment Needs Index were evaluated in all participants. The Fisher's Exact test and Mann-Whitney U test we used to establish the differences between groups. Low mean in all salivary parameters and a high caries frequency were observed in subjects with newly diagnosed rheumatoid arthritis compared to a control group $(p<0.01)$. The right maxillary second premolar 
$(n=6,46 \%, p=0.0100)$; right mandibular second premolar $(n=7,54 \%, p=0.0462)$ and left mandibular second molar $(n=10,77 \%, p=0.0001)$ were the most frequent teeth with caries. Early diagnosis and early treatment of rheumatoid arthritis can improve the prognosis in most of patients. The development of new public health policies and care based on the prevention are necessary to improve the quality of patient's lives.

KEYWORDS: Association; Rheumatoid arthritis; Early diagnosis; Prevention; Dental caries.

RESUMEN: Alteraciones en la saliva, trastornos de la articulación temporomandibular, disfagia, síndrome de Sjogren, caries dental, enfermedad periodontal y pérdida de dientes son algunas patologías que se han identificado en pacientes con artritis reumatoide. Los objetivos de este estudio fueron (1) Asociar la artritis reumatoide recientemente diagnosticada con la caries dentales e (2) Identificar los dientes más frecuentes con caries en los grupos de estudio. Se realizó un estudio piloto descriptivo. 620 participantes fueron evaluados, 29 sujetos cumplieron con los criterios de selección. Los sujetos se dividieron en 2 grupos: 13 sujetos con artritis reumatoide recién diagnosticados y 16 sujetos sin artritis reumatoide. En todos los participantes se evaluaron parámetros salivales, el índice CPOD, el índice IC, el índice FS-T y el índice INT. La prueba exacta de Fisher y U de Mann-Whitney se utilizaron para establecer diferencias entre grupos. En los resultados se observó un bajo promedio de los parámetros salivales y una alta frecuencia de caries en sujetos con artritis reumatoide recién diagnosticados comparados con un grupo control $(p<0.01)$. El segundo premolar superior derecho $(n=6,46 \%, p=0,0100)$; el segundo premolar mandibular derecho $(n=7,54 \%, p=0.0462)$ y el segundo molar mandibular izquierdo ( $n=10,77 \%, p=0.0001$ ) fueron los dientes más frecuentes con caries dental. El diagnóstico y el tratamiento temprano de la artritis reumatoide pueden mejorar el pronóstico en la mayoría de los pacientes. El desarrollo de nuevas políticas de salud pública basadas en la prevención de la cavidad bucal son necesarias para mejorar la calidad de vida de los pacientes.

PALABRAS CLAVE: Asociación; Artritis reumatoide; Reciente diagnóstico; Prevención; Caries dental.

\section{INTRODUCTION}

Rheumatoid arthritis (RA) is a progressive and destructive disease that affects more than $1 \%$ of the world's population. This autoimmune disease characterized by inflammation (synovitis), chronic pain and joint destruction, significantly reduces the quality and life expectancy of the subjects $(1,2)$. In recent years, the incidence and prevalence of RA has increased, affecting people of any age, sex and race, with high frequencies in white races and female patients with a ratio of 4 : 1 , therefore, out of every 4 people, 3 women have the disease $(1,2)$.

Myalgia, fatigue, fever, weight loss, depression and cardiorespiratory, dermatological, neurological, and digestive disorders are some general 
manifestations that have been reported in patients with arthritis (1-3).

In relation to oral manifestations, temporomandibular joint disorders, periodontal disease, dysphagia, Sjögren's syndrome, hyposalivation, xerostomia, dental caries, and tooth loss have been identified in patients with RA (4).

Sjogren's syndrome is one of the most common autoimmune diseases (5). The main clinical manifestations are: musculoskeletal pain, fatigue, dry eyes and dry mouth (6). The dry mouth symptom is caused mainly by the alteration of the salivary glands. This is due to a lymphocytic infiltration of the glandular tissue and the presence of autoantibodies that end up causing cellular and tissue damage to the glandular tissue (7).

Damage to the glandular tissue causes decreased salivary flow and the development of xerostomia. The presence of xerostomia in turn causes a greater accumulation of pathogens on the surfaces of the dental organs since the protective and regulatory properties of saliva are lost. These pathogens cause an increase in the incidence of cavities and even other diseases such as candidiasis (8)

Researchers have associated a high frequency of cavities in patients with RA. Saliva alterations and joint limitations are variables related to the presence and severity of dental caries in patients. Xerostomia, hyposalivation, and changes in the $\mathrm{pH}$ of the saliva $\mathrm{pH}$ are associated with an increase in bacteria such as streptococcus mutans, with the demineralization of the enamel, and with the development of carious lesions in the different teeth (9-11). On the other hand, the joint limitations of patients with RA are related to a diminished or null oral hygiene, an inadequate brushing technique and an incorrect handling of the toothbrush (11).
Authors have reported that general and oral clinical manifestations are related to the evolution of RA. Nowadays it is accepted that early diagnosis and early treatment of Rheumatoid Arthritis can improve the prognosis in most of patients $(2,12,13)$. Several researchers identified a high frequency of caries in recently diagnosed subjects and in subjects with several years of evolution of RA, however, in subjects with chronic RA was observed a high frequency of severe caries and an increase in tooth loss due to the presence of dental caries (12-15). Probably, the increase in the frequency of dental caries in recently diagnosed patients could explain the relationship between chronic RA and early tooth loss.

Unfortunately, after conducting a literature search on the topic, we identified a low frequency of studies related with the presence and severity of dental caries in subjects with newly diagnosed rheumatoid arthritis. Therefore, the aims of this research were 1) to study the association between newly diagnosed rheumatoid arthritis and dental caries and 2) to identify most frequent teeth with caries in study groups.

\section{MATERIALS AND METHODS}

This descriptive pilot study was performed from March to October 2019 at Regional Unit of Rheumatology and Osteoporosis of the Central Hospital Dr. Ignacio Morones Prieto in San Luis Potosi, Mexico. Based on the ethical principles of the Declaration of Helsinki, informed and voluntary written consent was obtained from the patients prior to the start of the study (16). The study was approved by the Ethical Committee of Central Hospital Dr. Ignacio Morones Prieto COFEPRIS $17 \mathrm{Cl} 24028093$ (code: 06-19) and by the Research Ethics Committee of the Faculty of Dentistry, Autonomous University of San Luis Potosi CONBIOETICA24CEI00120190213 (code: CIE-FE -012019). 


\section{STUDY POPULATION}

A total of 620 participants were evaluated to identify subjects who met the selection criteria. The participants were selected using a non-probability consecutive sampling. A total of 29 subjects fulfilled the following criteria: a) Inclusion. 1) Subjects with and without newly diagnosed rheumatoid arthritis; 2) both genders; 3) 25-70 years old and 4) with the presence of 28 teeth in mouth. Exclusion criteria included diagnosed inflammatory systemic diseases, autoimmune diseases, diabetic, cancer, smoking and pregnancy or nursing. The subjects were divided into 2 groups: 13 subjects with newly diagnosed rheumatoid arthritis and 16 subjects without rheumatoid arthritis.

\section{EVALUATION OF THE VARIABLES}

a) Newly diagnosed rheumatoid arthritis, b) salivary parameters and c) dental evaluations were performed in all participants using the following protocols:

- Subjects with newly diagnosed rheumatoid arthritis. The diagnosis early untreated rheumatoid arthritis was carried out by a rheumatologist, individuals who fulfilled the American College of Rheumatology (ACR) and European League Against Rheumatism (EULAR) classification criteria were included $(2,3)$. The DAS28 index was used to determine Rheumatoid Arthritis Disease Activity Score identifying the following variables: 1) tenderness and/or swelling in 28 joint counts, 2) erythrocyte sedimentation rate (ESR) and 3) a visual analogue scale (VAS). All subjects were classified as follow: low disease activity (DAS28ESR: $\leq 3.2$ ), moderate disease activity (DAS28ESR: $3.2-\leq 5.1$ ) and high disease activity (DAS28ESR: >5.1). A DAS $<2.6$ is considered to be in remission (17).

- Salivary parameters. The stimulated saliva flow rate was assessed between 9 a.m. and 12 p.m. to minimize diurnal variations associated with saliva sampling and at least 2 hours after dental brushing, eating or drinking. The subjects chewed a paraffin wax for 5 minutes and spitting the saliva collected in a Falcon graduated tube, the flow rate was measured and recorded in an electronic pH meter. Saliva pH of 6.6-7.1 was considered in normal range (18). The flow rate was calculated in millimeters per minute $(\mathrm{mL} /$ min). Subjects whose stimulated flow rate was less than $0.7 \mathrm{~mL} / \mathrm{min}$ were classified as hyposalivation (19).

- Dental evaluations. All volunteers received a routine clinical examination using a dental mirror and with artificial light. Clinical parameters of caries were recorded in all individuals, including the DMFT index, defined as the sum of the Decayed, Missing and Filled Teeth $(20,21)$. The care index $(\mathrm{Cl})$ provides a proportion of teeth that have been restored, was calculated as a proportion of the total number of decayed (D), missing (M) and filled (F) teeth ( $\mathrm{Cl}=\mathrm{F} / \mathrm{DMFT}$ ) (22). The FS-T index was defined as the number of teeth filled or crowned and calculated as the sum of filled (F) and sound (S) teeth (23). The Treatment Needs Index (TNI) for dental caries was determined as the proportion of untreated decayed teeth, and teeth treated with any kind of restorations or missing teeth caused by caries (24).

\section{STATISTICAL ANALYSES}

Before the start of the study, the examiner was calibrated with all the variables. The intraclass correlation coefficients and kappas obtained during the calibration were greater than 0.80 . Categorical variables were reported as frequencies and percentages, while continuous variables were reported as means, standard deviations (mean \pm standard deviations) and limits. Shapiro-Wilk and Brown-Forsythe tests were performed to determine the distribution of the variables. We used the Fisher's Exact test and Mann-Whitney $U$ test 
to establish the differences between groups. Data was analyzed using JMP ver. 15 (SAS Institute, Cary, NC) statistical software.

\section{RESULTS}

Out of the 620 subjects evaluated, 29 met the selection criteria. The patients were divided into 2 groups: 13 subjects with newly diagnosed rheumatoid arthritis (92\% women, age mean $=45$, standard deviation $=8.0)$, and 16 subjects without rheumatoid arthritis (50\% women, age mean $=49$, standard deviation $=10$ ). In the group of subjects with newly diagnosed rheumatoid arthritis two subjects (15\%) with moderate disease activity and eleven (85\%) with high disease activity [DAS28 $=5.7 \pm 0.93$ (3.6-7.6)] were identified.
Table 1 shows Salivary parameters, DMFT Index, Treatment Needs Index, Care Index and Functional Status Index in subjects with and without Rheumatoid Arthritis. On comparing the study groups, we found statistically significant differences in the salivary parameters $(p<0.01)$ and in decayed teeth $(p=0.0097)$. Low mean in all salivary parameters [Total salivary flow, $52 \pm 2.0$ (1.50-9.0); salivary flow $\mathrm{mL} / \mathrm{min}, 1.0 \pm 0.4$ (0.30-1.8 hyposalivation) and $\mathrm{pH}$ salivary $7.0 \pm 0.4(6.5-8.1)]$ and a high mean of decayed teeth $(9 \pm 4)$ were observed in the subjects with rheumatoid arthritis.

Range (Min Value-Max Value) of decayed teeth, type of tooth with high frequency of dental caries and oral diagnosis in subjects with and without rheumatoid arthritis are shown in Table 2.

Table 1. Salivary parameters, DMFT Index, Treatment Needs Index, Care Index and Teeth Filled and Sound Index in subjects with and without Rheumatoid Arthritis.

\begin{tabular}{|c|c|c|c|}
\hline \multirow[t]{2}{*}{ Groups } & $\begin{array}{c}\text { Subjects with Rheumatoid } \\
\text { Arthritis } n=13 \\
(100 \%)\end{array}$ & $\begin{array}{l}\text { Subjects without Rheuma- } \\
\text { toid Arthritis } n=16(100 \%)\end{array}$ & \\
\hline & \multicolumn{2}{|c|}{ Mean \pm Standard Deviation (Limits) } & $p$-value \\
\hline \multicolumn{4}{|l|}{ Salivary parameters } \\
\hline Total Salivary Flow mL & $5.2 \pm 2.0(1.50-9.0)$ & $11.6 \pm 1.5(8.5-14)$ & $<0.001$ \\
\hline Salivary Flow mL/min & $1.0 \pm 0.4(0.30-1.8)$ & $2.3 \pm 0.3(1.7-2.8)$ & $<0.001$ \\
\hline pH salivary & $7.0 \pm 0.4(6.56-8.1)$ & $7.4 \pm 0.2(7.0-7.2)$ & $<0.010$ \\
\hline \multicolumn{4}{|l|}{ Teeth } \\
\hline Healthy & $13 \pm 5(7-21)$ & $15 \pm 5(7-24)$ & NS \\
\hline Decayed & $9 \pm 4(1-19)$ & $5 \pm 4(0-17)$ & $<0.010$ \\
\hline Missing & $2 \pm 2(0-9)$ & $2 \pm 3(0-11)$ & NS \\
\hline Filled & $2 \pm 4(0-13)$ & $5 \pm 5(0-14)$ & NS \\
\hline Cl Index & $17 \pm 30(0-92)$ & $46 \pm 40(0-81)$ & NS \\
\hline TNI Index & $102 \pm 4(100-111)$ & $85 \pm 42(0-114)$ & NS \\
\hline FS-T Index & $13 \pm 4(7-21)$ & $15 \pm 5(9-24)$ & NS \\
\hline DMFT Index & $0.51 \pm 0.14(0.28-0.71)$ & $0.44 \pm 0.17(0.14-0.67)$ & NS \\
\hline
\end{tabular}

$\mathrm{n}=2$ 29. Statistical test used: Mann-Whitney U. Care Index (CI), Treatment Needs Index (TNI), Teeth Filled and Sound Index (FS-T), and DMFT Index (Decayed, Missing and Filled Teeth). No Significant: NS. 
a) $100 \%(n=13)$ of the subjects with rheumatoid arthritis had caries ( $p=0.0045)$; b) $38 \%$ of the subjects presented between 11-15 (range) caries $(p=0.0341)$; and $c)$ the most frequent teeth with caries were: 1 . the right maxillary second premolar $(n=6,46 \%, p=0.0100) ; 2$. ight mandibular second premolar $(n=7,54 \%, p=0.0462)$ and 3. left mandibular second molar $(n=10,77 \%, p=0.0001)$.

Table 2. Range of decayed teeth, type of tooth with high frequency of dental caries and oral diagnosis in subjects with and without Rheumatoid Arthritis.

\begin{tabular}{|c|c|c|c|c|}
\hline Groups & $\begin{array}{l}\text { Subjects with } \\
\text { Rheumatoid } \\
\text { Arthritis }\end{array}$ & $\begin{array}{l}\text { Subjects without } \\
\text { Rheumatoid } \\
\text { Arthritis }\end{array}$ & & \\
\hline Variables & Frequency (\%) & & Total & $p$-value \\
\hline \multicolumn{5}{|l|}{ a) Range of decayed teeth } \\
\hline $0-4$ & $3(23)$ & $10(62)$ & $13(45)$ & \\
\hline $5 \geq$ & $10(77)$ & $6(38)$ & $16(55)$ & $<0.050$ \\
\hline \multicolumn{5}{|l|}{ Total n } \\
\hline \multicolumn{5}{|c|}{ b) Most frequent tooth with dental caries } \\
\hline Right Maxillary Second Premolar & $6(46)$ & $1(6)$ & & $<0.010$ \\
\hline Right Mandibular Second Premolar & $7(54)$ & $3(19)$ & & $<0.050$ \\
\hline Left Mandibular Second Molar & $10(77)$ & $1(6)$ & & $<0.001$ \\
\hline Total n & $13(100)$ & $16(100)$ & & \\
\hline \multicolumn{5}{|l|}{ c) Oral Diagnosis } \\
\hline Healthy & 175 (48) & $248(56)$ & $423(52)$ & NS \\
\hline Missing & $29 \quad(8)$ & 31 (6) & $60(7)$ & NS \\
\hline Filled & $32 \quad(9)$ & $89(20)$ & $121(15)$ & NS \\
\hline Decayed & $127 \quad(35)$ & $80(18)$ & $207(26)$ & $<0.010$ \\
\hline Total n & 363 (100) & 448 (100) & 811 (100) & \\
\hline
\end{tabular}

$\mathrm{n}=29$ subjects with a total of 811 teeth. Statistical test used: Fisher's Exact test. No Significant: NS.

\section{DISCUSSION}

Arthritis is a chronic and highly destructive disease that affects the quality of patients' lives (2). In the oral cavity, alterations of the temporomandibular joint, Sjogren's syndrome, periodontitis, caries, tooth loss and cranial neuropathy are some of the alterations observed in patients (3,5-8, 12,14). The aims of this research were 1) to study the association between newly diagnosed rheuma- toid arthritis and dental caries and 2) to identify most frequent teeth with caries in study groups.

\section{DENTAL CARIES AND RHEUMATOID ARTHRITIS (RA)}

Dental caries is characterized by the progressive demineralization of the enamel caused by the fermentation of carbohydrates by acidic bacteria. One of the main bacteria associated with caries is the streptococcus mutans, however, a wide 
variety of microorganisms that intervene in dental caries have been identified by various researchers $(25,26)$. Poor dental hygiene habits, alterations in saliva, systemic diseases, socioeconomic factors, age, gender and nutrition are some of the variables related to the presence of cavities $(5-8,27)$.

In this study, when comparing subjects with newly diagnosed rheumatoid arthritis and subjects without RA in relation to dental caries, we observed statistically significant differences $(p<0.01)$, identifying a high frequency of caries (caries range: 11-15 teeth, 38\%) in subjects with newly diagnosed rheumatoid arthritis compared to the control group (caries range: $0-4$ teeth, 62\%). This finding seems to coincide with previous reports in Mexican patients. For example, González-Chávez, Susana Aideé, et al., reported a high frequency of caries (98.3\%) in patients diagnosed with RA with an average evolution time of 8 years of the disease. In both studies, a high frequency of caries was observed for the recently diagnosed subjects and for the subjects with an average of 8 years of evolution of the disease, however, GonzálezChávez, Susana Aideé, et al., Identified a 53\% of cases with severe dental caries and a $73 \%$ of tooth loss due to the presence of dental caries (14).

Kim, Ji-Won, et al., conducted a study with 157 RA patients and 20,140 healthy subjects. The authors did not find an association between RA and periodontal disease however did identify an association between RA and tooth loss. Probably, an increase in the frequency of caries in recently diagnosed patients could explain the relationship between chronic RA and tooth loss (15).

On the other hand, the article entitled: Temporomandibular and odontological abnormalities in patients with rheumatoid arthritis in Mexican population was reported by GonzálezChávez, Susana Aideé, et al. The study found a statistically significant difference, observing a higher frequency of caries in the group of patients with RA $(p<0.001)$. In addition, the researchers reported that molar teeth were the most frequent teeth with dental caries. The above data matches our results. We identified a high frequency of cavities and the most frequent teeth with cavities were molar teeth, specifically in the second lower left molar (28).

Studies carried out in other parts of the world also show results that coincide with those reported by us. De Azevedo Branco, et al; carried out a study in Brazilian population, in which they compared the oral health status of 42 patients with RA and 70 without RA. The authors found that RA patients had a more deteriorated oral health status compared to healthy patients. The researchers observed a higher frequency of teeth with cavities $(p=0.038)$ in RA patients (29).

Merle, et al. conducted a study in Germany where they analyzed the oral health of 59 adolescents with RA. The authors did not include a control group, and only compared their results with epidemiological studies in healthy German patients. When making this type of comparison, the authors found that patients with juvenile rheumatoid arthritis had a higher prevalence of caries (30). Furthermore, Äyräväinen, et al.; conducted a prospective cohort study. The investigators included 53 untreated newly diagnosed rheumatoid arthritis patients (control group) and 28 chronic rheumatoid arthritis patients. The authors found a high frequency of caries in both groups, identifying a higher presence of xerostomia in patients with chronic RA (12).

Some variables associated with the high frequency of dental caries in subjects with RA are:

1. Alterations in saliva, 2. Poor oral hygiene, 3. Presence of microorganisms, 4. Alterations of the enamel structure, 5. Evolution of rheumatoid arthritis (natural history of the disease), 6. Age and socioeconomic factors, 7. Osteoarthritis in fingers 
and hands and 8 . General osteoarthritis causing severe immobility in the patient $(5-9,10,12,31-34)$.

In relation to oral saliva, we observed statistically significant differences in all variables. Our results showed decreased salivary flow and a more acidic pH in RA patients. Several authors have reported that alterations in salivary parameters are associated with acidogenic bacteria, with demineralization of dental enamel and the development of carious lesions. Khan, et al. analyzed the changes in salivary $\mathrm{pH}$ in dental caries and periodontitis, as well as the possible use of salivary pH as a biomarker for the diagnosis of the previously mentioned diseases. The authors reported the presence of an acidic $\mathrm{pH}$ in patients with dental caries $(\mathrm{pH}=6.08 \pm 0.12)(5-8,9,10)$.

\section{MOST FREQUENT TEETH WITH CARIES IN SUBJECTS WITH RHEUMATOID ARTHRITIS}

In this study, the most frequent teeth with caries were: 1 . the right maxillary second premolar $(n=6,46 \%, p=0.0100) ; 2$. right mandibular second premolar $(n=7,54 \%, p=0.0462)$ and 3. left mandibular second molar $(n=10,77 \%, p=0.0001)$. The high frequency of caries in molars and premolars coincides with previous reports. Authors have reported that a) the occlusal anatomy of the teeth (pits and fissures) favor the retention of bacterial plaque and b) the location and position of the teeth make the tooth brushing technique difficult $(28,35)$.

\section{DENTAL CARIES AND RHEUMATOID ARTHRITIS. CONTROVERSY}

Although various researchers have reported an association between caries and $\mathrm{RA}$, this remains a controversial topic, as there are also studies that contradict the association. For example, Skeie, et al. conducted a systematic review and meta-analysis in which 19 articles met the inclusion criteria.
Of these 19 articles, 8 evaluated the frequency of caries in children and adolescents with RA. Of those 8 articles, 3 studies reported statistically significant differences, while 5 articles found no differences between dental caries and RA. A possible explanation for the absence of differences between groups could be the various techniques or guides used to assess the presence or absence of caries. Therefore, it is necessary to carry out epidemiological studies with unified criteria to evaluate the presence or absence of dental caries (36).

\section{CLINICAL APPLICATION}

Authors have reported that the presence of dental caries is associated with the quality of life of patients $(37,38)$. We observed alterations in the different parameters of saliva and a high frequency of dental caries in subjects with newly diagnosed rheumatoid arthritis compared with a control group, the previous results could be related to the association between subjects with chronic rheumatoid arthritis and tooth loss. Therefore, it is necessary to carry out studies and multivariate analysis to identify associations.

Early diagnosis and early treatment of AR can improve the prognosis in most patients (2). The development of new public health policies and care based on the prevention of oral diseases are necessary to improve the quality of life of patients.

\section{STUDY LIMITATIONS}

a) The study is descriptive, b) Multivariate analyzes were not calculated due to lack of statistical power and to a limited number of participants, c) The results should not be interpreted as definitive because the bivariate analyzes do not include all the factors of confusión and d) The lack of association in multivariate studies could explain the absence of a relationship between Rheumatoid arthritis and dental caries. 


\section{CONCLUSIONS}

a) A high frequency of caries was observed in subjects with newly diagnosed rheumatoid arthritis compared to a control group $(p<0.01)$. b) Left mandibular second molar $(n=10,77 \%, p=0.0001)$ was the most frequent teeth with dental caries.

\section{AUTHOR CONTRIBUTION STATEMENT}

Conceptualization and design: A.G.S.M., F.M.G., M.U.M.M., M.F.S.O., L.D.V.G. and N.P.M.

Literature review: A.G.S.M., F.M.G., M.U.M.M., M.F.S.O., L.D.V.G. and N.P.M.

Methodology and validation: F.M.G. and N.P.M. Formal analysis: A.G.S.M., F.M.G. and N.P.M. Investigation and data collection: A.G.S.M., F.M.G., M.U.M.M., M.F.S.O., L.D.V.G.

Resources: F.M.G. and M.U.M.M., Data analysis and interpretation: A.G.S.M., F.M.G., M.U.M.M. and N.P.M.

Writing-original draft preparation: All authors. Writing-review \& editing: All authors.

Supervision: N.P.M.

Project administration: F.M.G. and M.U.M.M.

Funding acquisition: F.M.G. and M.U.M.M.

\section{REFERENCES}

1. Aideé S., Chávez G., Pacheco C., Teresita T., Caraveo DJ. Oral health and orofacial function in patients with rheumatoid arthritis. Rheumatol Int . 2020; 40 (3): 445-53.

2. Krasselt M., Baerwald C. Sex, symptom severity, and quality of life in rheumatology. Clin Rev Allergy Immunol. 2019; 56 (3): 346-61.

3. Reis T.R.C., Nogueira B.M.L., Domínguez M.C.L., de Menezes S.A.F., da Silva e Souza P. de A.R., Menezes T.O de A. Oral Manifestations of Rheumatologic Patients: A
Knowledge Review. Int J Odontostomatot. 2015; 9 (3): 413-8.

4. Gualtierotti R., Marzano A.V., Spadari F., Cugno M.. Main Oral Manifestations in Immune-Mediated and Inflammatory Rheumatic Diseases. J Clin Med. 2018; 8 (21): 1-19.

5. Vivino F.B. Sjogren's syndrome: Clinical aspects. Clin Immunol. 2017;182: 48-54.

6. Vivino F.B., Bunya V.Y., Massaro-Giordano G., Johr C.R., Giattino S.L., Schorpion A, et al. Sjogren's syndrome: An update on disease pathogenesis, clinical manifestations and treatment. Clin Immunol Orlando Fla. 2019; 203: 81-121.

7. Hsu C.Y., Hung K.C., Lin M.S., Ko C.H., Lin Y.S., Chen T.H., et al. The effect of pilocarpine on dental caries in patients with primary Sjögren's syndrome: a database prospective cohort study. Arthritis Res Ther. 2019; 21 (1): $1-10$.

8. Berman N., Vivino F., Baker J., Dunham J., Pinto A. Risk factors for caries development in primary Sjogren syndrome. Oral Surg Oral Med Oral Pathol Oral Radiol. 2019; 128 (2): $117-22$.

9. Khan M., Muglikar S., Kale R., Aziz S., Shaikh F., Sheikh A. Comparative Assessment of Salivary pH as a Diagnostic Marker in Dental Caries and Chronic Periodontitis. Int J Res Rep Dent. 2021; 33-7.

10. Singh S., Sharma A., Sood P., Sood A., Zaidi I., Sinha A. Saliva as a prediction tool for dental caries: An in vivo study. J Oral Biol Craniofacial Res. 2015; 5 (2): 59-64.

11. Thomas D.C., Kohli M.D., Chen M.D.S.N., Peleg H., Almoznino G. Orofacial manifestations of rheumatoid arthritis and systemic lupus erythematosus: a narrative review. Quintessence Int. 2021; 52 (5): 454-66.

12. Äyräväinen L., Heikkinen A.M., Kuuliala A., Ahola K., Koivuniemi R., Peltola J., et 
al. Activity of rheumatoid arthritis correlates with oral inflammatory burden. Rheumatol Int. 2018; 38 (9):1661-9.

13. Olivieri M., Gerardi M.C., Spinelli F.R., Franco M.D. A Focus on the Diagnosis of Early Rheumatoid Arthritis. Int J Clin Med. 2012; (3): 650-4.

14. González-Chávez S.A., Pacheco-Tena C., Caraveo-Frescas T.J., Quiñonez-Flores C.M., Reyes-Cordero G., Campos-Torres R.M. Oral health and orofacial function in patients with rheumatoid arthritis. Rheumatol Int. 2020; 40 (3): 445-53.

15. Kim J.W., Park J.B., Yim H.W., Lee J., Kwok S.K., Ju J.H., et al. Rheumatoid arthritis is associated with early tooth loss: results from Korea National Health and Nutrition Examination Survey V to VI. Korean J Intern Med. 2019; 34 (6):1381.

16. World Medical Association. Declaration of Helsinki, Ethical Principles for Scientific Requirements and Research Protocols. Bulletin of the World Health Organization [Internet]. 2013; 79 (4): 373. Available from: https://www.wma.net/policies-post/ wma-declaration-of-helsinki-ethical-principles-for-medical-research-involving-humansubjects.

17. van Riel P.L.C.M., Renskers L. The Disease Activity Score (DAS) and the Disease Activity Score using 28 joint counts (DAS28) in the management of rheumatoid arthritis. Clin Exp Rheumatol. 2016; 34 (4): 40-4.

18. Zhang C.Z., Cheng X.Q., Li J.Y., Zhang P., Yi P., Xu X., et al. Saliva in the diagnosis of diseases. Int J Oral Sci. 2016; 8 (3): 133-7.

19. Islas-Granillo H., Borges-Yáñez A., Fernández-Barrera M.Á., Ávila-Burgos L., PatiñoMarín N., Márquez-Corona M.L., et al. Relationship of hyposalivation and xerostomia in Mexican elderly with socioeconomic, sociodemographic and dental factors. Sci Rep. 2017; 17; 7 (1): 40686.

20. World Health Organization. (1997)! Oral health surveys: basic methods, 4th ed. World Health Organization. Vol. 11, World Health Organization.

21. Bratthall D. Introducing the Significant Caries Index together with a proposal for a new global oral health goal for 12-year-olds. Int Dent J. 2000; 50 (5): 378-84.

22. Bird J., Marshman Z. Dental caries experience, care index and restorative index in children with learning disabilities and children without learning disabilities: a systematic review and meta-analysis. Evid Based Dent. 2020; 21 (1):16-7.

23. Schuller A.A., Holst D. Oral status indicators DMFT and FS-T: Reflections on index selection. Eur J Oral Sci. 2001; 109 (3):155-9.

24. Medina-Solís C.E., Pontigo-Loyola A.P., Mendoza-Rodríguez M., Lucas-Rincón S.E., Márquez-Rodríguez S., Navarrete-Hernandez J.J., et al. Treatment needs for dental caries, restorative care index, and index of extractions in adolescents 12 and 15 years old. West Indian Med J. 2013; 62 (7): 636-41.

25. Mattos-Graner R.O., Klein M.I., Smith D.J. Lessons learned from clinical studies: roles of mutans streptococci in the pathogenesis of dental caries. Curr Oral Health Rep. 2014; 1 (1): 70-8.

26. Esberg A., Johansson L., Johansson I., Dahlqvist S.R. Oral Microbiota Identifies Patients in Early Onset Rheumatoid Arthritis. Microorganisms 2021; 9 (8): 1657.

27. Pitts N.B., Zero D.T., Marsh P.D., Ekstrand K., Weintraub J.A., Ramos-Gomez F., et al. Dental caries. Nat Rev Dis Primer. 2017; 3 (1): 1-16.

28. González-Chávez S.A., Pacheco-Tena C., Torres R.M.C., Quiñonez-Flores C.M., 
Reyes-Cordero G., Caraveo-Frescas T.J. Temporomandibular and odontological abnormalities in patients with rheumatoid arthritis. Reumatol Clín (Engl Ed). 2020; 16 (4): 262-71.

29. De Azevedo Branco L.G., Oliveira S.R., Corrêa J.D., Calderaro D.C., Mendonça S.M.S., de Queiroz Cunha F., et al. Oral health-related quality of life among individuals with rheumatoid arthritis. Clin Rheumatol. 2019; 38 (9): 2433-41.

30. Merle C.L., Hoffmann R., Schmickler J., Rühlmann M., Challakh N., Haak R., et al. Comprehensive Assessment of Orofacial Health and Disease Related Parameters in Adolescents with Juvenile Idiopathic Arthritis-A Cross-Sectional Study. J Clin Med. 2020; 9 (2): 513.

31. Emami E., de Souza R.F., Kabawat M., Feine J.S. The impact of edentulism on oral and general health. Int J Dent. 2013; 2013: 498305.

32. Welbury R., Thomason J., Fitzgerald J., Steen I., Marshall N., Foster H. Increased prevalence of dental caries and poor oral hygiene in juvenile idiopathic arthritis. Rheumatology (Oxford). 2003; 42 (12): 1445-51.

33. Kelsey J.L., Lamster I.B. Influence of musculoskeletal conditions on oral health among older adults. Am J Public Health. 2008; 98 (7): 1177-83.

34. González-Chávez S.A., Pacheco-Tena C., Caraveo-Frescas T.J., Quiñonez-Flores C.M., Reyes-Cordero G., Campos-Torres R.M. Oral health and orofacial function in patients with rheumatoid arthritis. Rheumatol Int. 2020 Mar; 40 (3): 445-453.

35. Nazir M.A., Bakhurji E., Gaffar B.O., Al-Ansari A., Al-Khalifa K.S. First Permanent Molar Caries and its Association with Carious Lesions in Other Permanent Teeth. J Clin Diagn Res. 2019; 13 (1).

36. Skeie M.S., Gil E.G., Cetrelli L., Rosén A., Fischer J., Åstrøm A.N., et al. Oral health in children and adolescents with juvenile idiopathic arthritis-a systematic review and meta-analysis. BMC Oral Health. 2019; 19 (1): 285 .

37. Costa S.M., Vasconcelos M., Abreu M.H.N.G. Impact of dental caries on quality of life among adults resident in greater Belo Horizonte, State of Minas Gerais, Brazil. Cienc Saude Colet. 2013; 18 (7): 1971-80.

38. Batista M.J., Perianes L.B.R., Hilgert J.B., Hugo F.N., de Sousa M.L.R. The impacts of oral health on quality of life in working adults. Braz Oral Res. 2014; 28: 1-6. 